\title{
COMPARAÇÃO DE FLUXOS EM SISTEMAS DE LÂMPADA UV PARA TRATAMENTO DE ÁGUA DE CAPTAÇÃO DE FRUTAL/MG
}

\author{
RODRIGUES, Raiane Maria Araujo ${ }^{1}$; MARTINS, Heytor Lemos ${ }^{2}$; MILLAN, Rodrigo \\ $\mathrm{Ney}^{3}$; FUJITA, Allynson Takehiro ${ }^{4}$
}

\section{doi> 10.33726/akdpapers2447-7656v8a52019p153-164}

RESUMO: As fontes de contaminação antropogênicas nos mananciais são, em geral, diretamente associadas a despejos domésticos e industriais. Estes se agravam devido ao chorume, oriundo de aterros de resíduos sólidos, às fezes de animais que contaminam os lençóis freáticos com microrganismos patogênicos e/ou poluentes orgânicos persistentes (FREITAS \& ALMEIDA, 1998; MORA et al., 2011; TANG et al., 2013) e, também, por meio de potenciais fontes de nitrato e substâncias orgânicas extremamente tóxicas ao homem e ao meio ambiente (GRIMALT et al., 2004; BOUÉTARD et al., 2013). Neste sentido, o projeto visa otimizar o fluxo de um sistema de tratamento de água, realizado com lâmpada UV (tipo luz germicida) de baixo custo. Será testada uma lâmpada de 15 w Germicida, com três fluxos diferentes e de fontes diferentes. Serão realizadas análises de coliformes termotolerantes e variáveis físicas e químicas da água, antes e após o tratamento. O fluxo mais eficiente será divulgado na parte de resultados e, futuramente, poderá se tornar uma alternativa de tratamento de água para consumo em propriedades rurais e em pequenas comunidades.

PALAVRAS-CHAVE: Radiação UV, coliformes termotolerantes, variáveis físicas e químicas, qualidade de água

ABSTRACT: Anthropogenic sources of contamination in water sources are generally directly associated with domestic and industrial dumping. These are aggravated by manure from solid waste landfills, animal feces that contaminate groundwater with pathogenic microorganisms and / or persistent organic pollutants (FREITAS \& ALMEIDA, 1998; MORA et al., 2011; TANG et al., 2013) and also through potential sources of nitrate and extremely toxic substances to humans (GRIMALT et al., 2004; BOUÉTARD et al., 2013). In this sense, the project aims to optimize the flow of a water treatment system, made with low cost UV lamp (germicidal light). A 15w Germicide lamp with three different streams from different sources will be tested. Thermotolerant coliforms and physical and chemical water variables will be analyzed before and after treatment. The most efficient flow will be reported in the results part and in the future could become an alternative treatment for drinking water on farms and small communities.

KEYWORDS: UV radiation, thermotolerant coliforms, physical and chemical variables, water quality

\footnotetext{
${ }^{1}$ Graduada em Tecnologia em Alimentos: raianearaujorodrigues97@gmail.com

${ }^{2}$ Mestrando em Ciências Ambientais: heytor.martins@uemg.br

${ }^{3}$ Doutor em Microbiologia Agropecuária: rodrigo.millan@uemg.br

${ }^{4}$ Doutor em Química Analítica: allynson.fujita@uemg.br
} 


\section{INTRODUÇÃO}

Segundo a Declaração Universal dos Direitos da Água, "o direito a água é um dos direitos fundamentais do ser humano". É, sobretudo, um direito à vida, tal qual é estipulado no artigo trigésimo da Declaração Universal dos Direitos do Homem (MINISTÉRIO DO MEIO AMBIENTE, 2000). É fato que as atividades humanas, associadas a um estilo de vida consumista e ao desperdício, têm determinado alterações significativas ao meio ambiente, influenciando nas reservas dos recursos naturais (DONAIRE, 2001).

A água, em alguns territórios, tem se tornado um recurso escasso e com qualidade comprometida. Os crescentes desmatamentos, os processos de erosão/assoreamento dos mananciais superficiais, os lançamentos de efluentes e detritos industriais e domésticos nos recursos hídricos têm contribuído para tal situação (MACKERETH; HERON; TALLING, 1978).

Nos países em desenvolvimento, essa problemática é agravada em razão da baixa cobertura da população quanto aos serviços de segurança hídrica, relativos ao abastecimento de água com qualidade e quantidade. No entanto, existe uma distribuição desigual do serviço entre as diversas regiões do país, entre a população urbana e a rural e ainda entre os municípios.

O acesso aos serviços de abastecimento de água decresce, a partir das Regiões Sudeste e Sul para o Nordeste e Norte, sendo que temos os menores índices nesta última (MORMUL et al. 2006).

O acesso da população urbana também diminui, face à rural, do mesmo modo em que se diferenciam entre os municípios de maior população para os de menor contingente populacional. Nas áreas urbanas, a cobertura decai, especialmente se observarmos do centro para a periferia. O decréscimo ocorre, ainda, social e economicamente, partindo-se dos ricos para os pobres (NORDBERG; GOYER; CLARCKSON, 2006).

A ocupação urbana e rural descontroladas, marcadamente em suas áreas de proteção, tem sido a maior ameaça aos mananciais. Tal ocupação expõe o descuido com o esgoto doméstico, com os resíduos sólidos e com a carga urbana difusa de 
poluição, levando ao comprometimento da qualidade da água bruta e à possível inviabilização de uso do manancial, dado o aumento do custo do tratamento e também à ameaça de redução da qualidade da água a ser distribuída para a população, particularmente devido à possível presença de substâncias tóxicas e microrganismos patogênicos associados à poluição e contaminação (SILVA \& PORTO, 2003).

Segundo Lima e Zakia (2000), as atitudes comportamentais do homem, desde que ele se tornou parte dominante dos sistemas, têm uma tendência em sentido contrário à manutenção do equilíbrio ambiental. Isto talvez tenha origem no fato de que ele não pode criar as fontes que satisfaçam às suas necessidades fora do sistema ecológico, daí, então, que essa contingência lhe impõe uma pressão cada vez maior em sua relação com o ambiente.

A contaminação das águas naturais pode ocorrer em qualquer fase do ciclo hidrológico, esteja ela tanto no estado de vapor em contato com a atmosfera quanto no estado líquido, seja no movimento descendente (chuva ou neve), seja no contato com a crosta e, infelizmente, cada vez mais, em decorrência das atividades antropogênicas (TUNDISI, 2006).

Desse modo, o trabalho teve como objetivo otimizar um equipamento com sistemas de lâmpadas UV, do tipo germicida, para o tratamento de água superficial e subterrâneas (cisterna), a fim de quantificar os coliformes termotolerantes na água a ser tratada e, após, tratamento e determinação de variáveis físicas e químicas da água, tais como: $\mathrm{pH}$, oxigênio dissolvido, salinidade, condutividade elétrica, resistividade elétrica, potencial redox, sólidos totais dissolvidos e temperatura.

\section{PROCEDIMENTO EXPERIMENTAL}

Foram selecionadas amostras de água de uma fonte lótica, na qual o fluxo foi otimizado para apresentar maior eficiência na eliminação de coliformes termotolerantes. 
A proposta foi a de montar um sistema com tubo PVC de $75 \mathrm{~mm}$ de diâmetro, e utilizar lâmpadas do tipo germicida (15 w), as quais emitem, no comprimento, ondas ultravioletas, para eliminar as bactérias termotolerantes, em água de cisterna e águas superficiais, oriundas de propriedades rurais do município de Frutal - MG.

\section{Figura 1 - Protótipo do sistema de tratamento e imagem do mesmo}
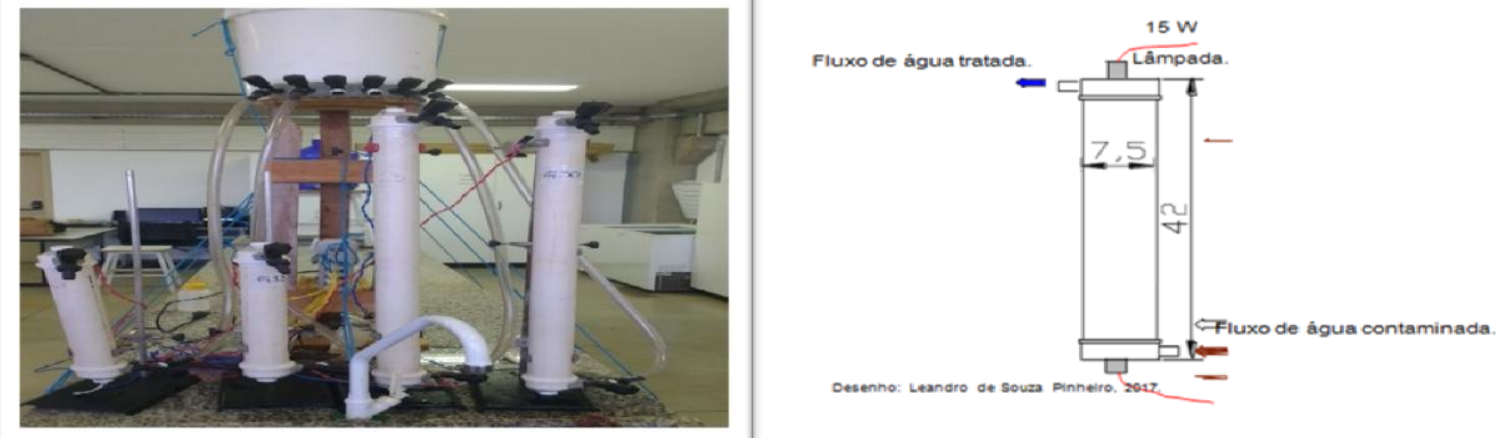

Foram montados os sistemas de tratamento e de otimização das condições de utilização, melhorando o fluxo de água a ser tratada, a quantificação dos microrganismos termotolerantes e variáveis físico-químicas de qualidade de água utilizando lâmpada germicida.

Testes foram realizados em uma lâmpada de $15 \mathrm{w}$ em formatos tubulares. $\mathrm{A}$ lâmpada foi inserida em tubos PVC de $75 \mathrm{~mm}$ para permitir que a amostra de água pudesse ficar diretamente em contato com a lâmpada, conforme é mostrado na figura 1.

Para os testes com a lâmpada com três valores de fluxo (F1, F2 e F3), sendo 3, 6 e 12 L/h, com triplicatas, deverão ser coletados $60 \mathrm{~L}$ de água de um mesmo local.

Foi determinada a concentração de fósforo total, ortofosfato, nitrato, nitrito e amônia por espectrofotometria UV/VIS, de acordo com Golterman et al. (1978) e Koloreff (1976).

As amostras para a quantificação dos nutrientes foram congeladas imediatamente após as coletas e analisadas em menos de uma semana após a coleta. 
A amostra de água foi analisada antes e depois do tratamento. Os resultados foram anotados e tratados estatisticamente.

Todas as amostras de água utilizadas nos ajustes do sistema foram avaliadas, bem como os parâmetros determinados na sonda multiparâmetros de qualidade de água (HANNA HI9828) e a quantificação dos coliformes termotolerantes. Os parâmetros físicos e químicos foram medidos no local de amostragem, antes e após o tratamento implantado.

A análise microbiológica foi realizada em laboratório, após coleta de água no local (antes e após o tratamento) em frascos de vidro esterilizados.

Foi realizado treinamento para manusear a sonda multiparâmetros de qualidade de água (HANNA HI9828) e para realizar a quantificação de coliformes termotolerantes. A análise de nutrientes foi realizada com o acompanhamento técnico do laboratório da Unidade acadêmica de Frutal.

Foi utilizada água de sistema de captação do município de Frutal/MG.

Figura 2 - Ponto de coleta da água utilizada para a pesquisa

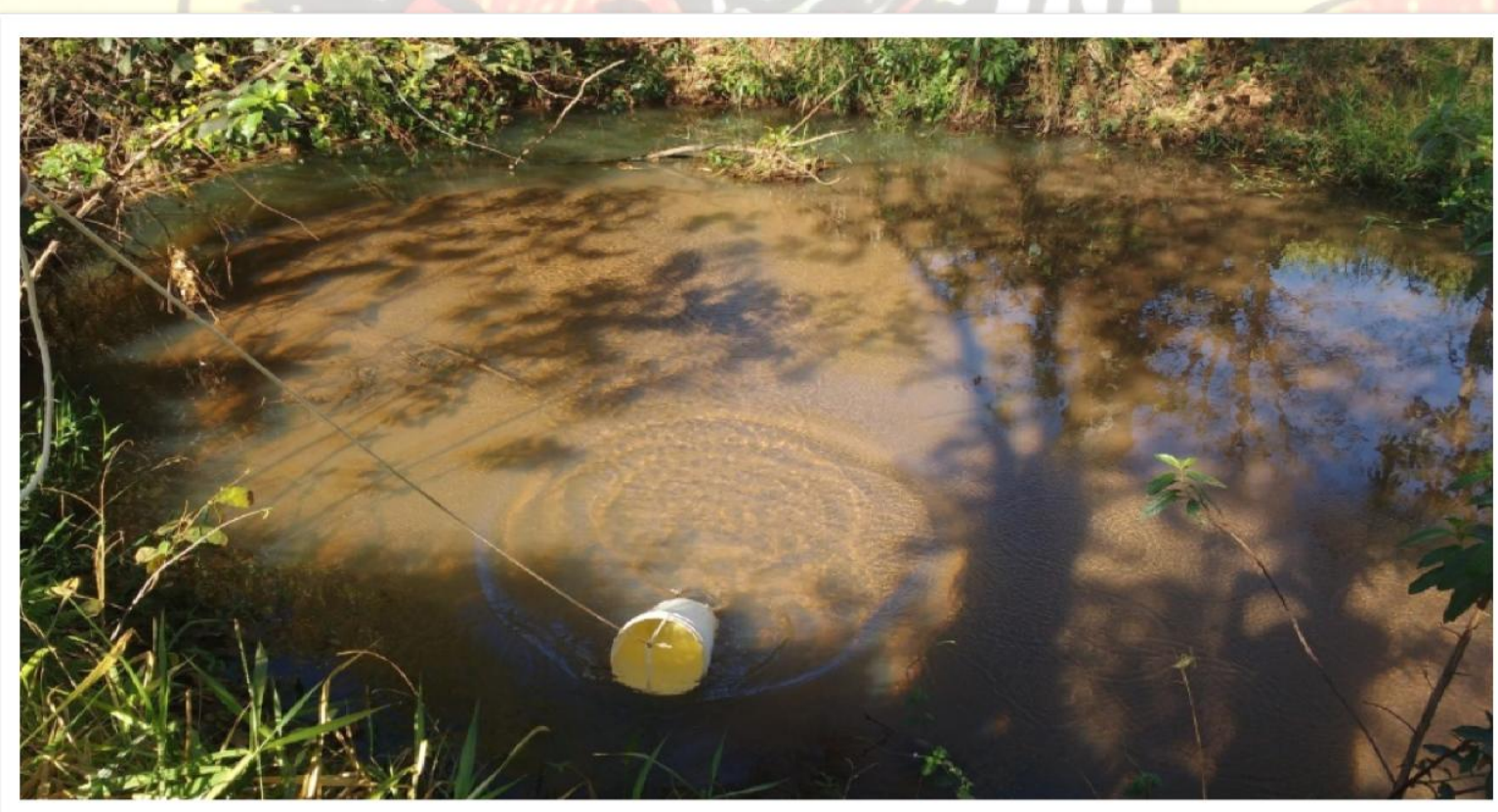




\section{VARIÁVEIS ANALISADAS}

\subsection{Variáveis físicas e químicas}

Temperatura, $\mathrm{pH}$, condutividade e oxigênio dissolvido foram medidos com sonda multiparamétrica HANNA HI 9828, no local.

A amostragem de água para determinação de nutrientes ocorreu em frascos de polietileno, previamente limpos e com capacidade de armazenamento de $500 \mathrm{~mL}$. Fósforo total, nitrato, nitrito e amônia foram determinados espectrofotometricamente, de acordo com Golterman et al. (1978) e Koloreff (1976).

As amostras para a quantificação dos nutrientes foram congeladas imediatamente após as coletas e analisadas em menos de uma semana.

\subsection{Coliformes termotolerantes}

Frascos previamente esterilizados foram utilizados para a amostragem de água, a fim de se proceder à determinação dos coliformes termotolerantes. A quantificação ocorreu através da técnica dos tubos múltiplos, onde diluições decimais das amostras foram incubadas em 03 tubos de ensaio, contendo meio de cultura $\mathrm{A} 1$, os quais foram incubados por 03 horas em estufa, a $35^{\circ} \mathrm{C}$ e, posteriormente, em banho-maria, a $44,5^{\circ} \mathrm{C}$ por 21 horas. Os resultados foram verificados através da leitura dos tubos positivos na tabela de NMP/100 mL (APHA, 2005).

\section{RESULTADOS E DISCUSSÃO}

\section{Variáveis Físico-químicas}

$\mathrm{O} \mathrm{pH}$ é uma variável que mede a acidez da água e a sua variação pode depender das relações entre matéria orgânica depositadas nos corpos hídricos, seres vivos, rocha, ar e a própria água dos viveiros. A acidez da água pode estar 
associada também com a decomposição da matéria orgânica presente no curso d’água (BUCCI, OLIVEIRA, 2014).

A temperatura da água é uma variável de extrema importância para os estudos relacionados a corpos d'água, pois está associada ao consumo de oxigênio, e ao crescimento e sobrevivência de organismos presentes na água (BIOTTA; DANIEL, 2012).

Os níveis de oxigênio dissolvido não apresentaram diferença significativa $(p>0,05)$. Os valores de oxigênio ficaram dentro dos padrões estabelecidos pela resolução 357/2005 do CONAMA - Conselho Nacional do Meio Ambiente (BRASIL, 2005).

O oxigênio dissolvido é o principal parâmetro de caracterização dos efeitos da poluição das águas por despejos orgânicos (VON SPERLING, 1996).

A condutividade elétrica da água é representada em sua maioria por sólidos dissolvidos em água, dos quais se destacam dois tipos: compostos iônicos e compostos catiônicos. Os compostos iônicos (cargas negativas, que possuem elétrons livres na camada de valência), são sólidos que se dissolvem em água e são caracterizados como sendo cloretos, sulfatos, nitratos e fosfatos.

Os compostos catiônicos (cargas positivas, que perderam elétrons na camada de valência) também interferem na condutividade elétrica da água e possuem cátions de sódio, magnésio, cálcio, ferro, alumínio e amônio. Desta forma, quando mensuramos a condutividade elétrica de uma amostra, estamos na realidade quantificando uma grande quantidade de compostos nela contidos - uns positivos, outros negativos - e que, em solução, permitem a passagem da eletricidade.

Materiais orgânicos, como óleos, graxas, álcool, fenóis não possuem a capacidade de conduzir eletricidade. Assim, quando se apresentam na forma dissolvida na água, a condutividade elétrica é severamente reduzida, e chega a zero, quando o produto está em fase livre.

TDS significa total de sólido dissolvido (ou Total de Sais Dissolvidos), ou seja, tudo que compõe a água, porém, que não seja a própria água. TDS é uma medida que totaliza todos os sólidos dissolvidos inorgânicos e orgânicos em sua água.

Isso inclui vários componentes importantes, como cálcio, magnésio e carbonato, o qual pode ser medido usando testes de $\mathrm{kH}, \mathrm{gH}$, kits de $\mathrm{pH}$. No entanto, isso também inclui todos os outros minerais dissolvidos, sais e muito mais. 
O teste de salinidade é feito para determinar a quantidade de sais dissolvidos em uma amostra de água natural, como de oceanos, rios, lagos e mares. A salinidade permite determinar se a água está adequada para beber, bem como realizar o monitoramento ecológico de habitats aquáticos.

ORP é, basicamente, uma medida da carga molecular que confere ao nível da capacidade de uma substância de oxidar ou reduzir a oxidação. Uma carga ORP positivo indica que a substância é um oxidante. Quanto maior a carga positiva, mais forte será o poder oxidante. E, é pela medida da condutividade que se obtém a resistividade.

Tabela 1. Variáveis antes a após passar pelo tratamento.

\begin{tabular}{cccc}
\hline Variáveis /Fluxo & CONTROLE & F1 40L/h & F2 120L/h \\
\hline pH & $\mathbf{7 , 0 9}$ & $\mathbf{5 , 3 8}$ & $\mathbf{5 , 9 1}$ \\
Temperatura & $\mathbf{1 8 , 8 7}$ & $\mathbf{2 1}$ & $\mathbf{2 0 , 5 9}$ \\
OD & $\mathbf{9 , 8 3}$ & $\mathbf{9 , 4 4}$ & $\mathbf{8 , 8 8}$ \\
Cond. & $\mathbf{4 8}$ & $\mathbf{4 3}$ & $\mathbf{5 0}$ \\
TDS & $\mathbf{4 8}$ & $\mathbf{4 3}$ & $\mathbf{5 0}$ \\
Sal. & $\mathbf{0 , 0 2}$ & $\mathbf{0 , 0 2}$ & $\mathbf{0 , 0 2}$ \\
ORP & $-\mathbf{7 2 , 3}$ & $-88,4$ & $-66,3$ \\
Res. & 20,6 & $\mathbf{2 2 , 2}$ & $\mathbf{2 0 , 2}$ \\
\hline
\end{tabular}

\section{Coliformes Termotolerantes}

A quantidade de coliformes era baixa e estava dentro do estabelecido pela legislação, pois, segundo o Conselho Nacional do Meio Ambiente - CONAMA, sobre coliformes termotolerantes, diz que: para o uso de recreação de contato primário deverão ser obedecidos os padrões de qualidade de balneabilidade, previstos na Resolução CONAMA, nº 274, de 2000.

Para os demais usos, não deverá ser excedido um limite de 200 coliformes termotolerantes por 100 mililitros em $80 \%$ ou mais, de pelo menos 6 amostras, coletadas durante o período de um ano, com frequência bimestral. 
Tabela 2. Antes de passar pelo tratamento com lâmpada UV germicida, foram feitos três pontos e analisadas.

\begin{tabular}{cccc}
\hline Ponto/Diluição & 0 & -1 & -2 \\
\hline 1 & $\mathbf{4}$ & $\mathbf{1}$ & $\mathbf{0}$ \\
2 & $\mathbf{2}$ & $\mathbf{0}$ & $\mathbf{0}$ \\
3 & $\mathbf{2}$ & $\mathbf{1}$ & $\mathbf{0}$ \\
\hline
\end{tabular}

Tabela 3. Após passar pelo tratamento, a amostra Controle, Fluxo 1 e Fluxo 2, obtiveram resultado satisfatório, resultando em $100 \%$ de eficiência, sendo assim não foi quantificado coliformes.

\begin{tabular}{cccc}
\hline Ponto/FluXo & CONTROLE & $F 1$ & $F 2$ \\
\hline 1 & $\mathbf{0}$ & $\mathbf{0}$ & $\mathbf{0}$ \\
2 & $\mathbf{0}$ & $\mathbf{0}$ & $\mathbf{0}$ \\
3 & $\mathbf{0}$ & $\mathbf{0}$ & $\mathbf{0}$ \\
\hline
\end{tabular}

\section{Análise de Nutrientes}

A eutrofização artificial é ocasionada pelo aumento de nutrientes essenciais na água, principalmente os nitrogenados (amônia, nitrito, nitrato) e fosfatados (fósforo total e ortofosfato), que são de grande importância para a cadeia alimentar. Quando descarregados em altas concentrações, provindos de atividades antrópicas, geram alterações no corpo hídrico, como o aumento da turbidez da água, capaz de impedir que organismo produza o oxigênio resultante da fotossíntese, necessário para manter o equilíbrio do corpo hídrico.

A diminuição do oxigênio dissolvido em consequência da poluição pode ocasionar a ausência de espécies, principalmente as de vertebrados, como os peixes.

O excesso de nutrientes causa o crescimento excessivo de macrófitas flutuantes, floração de algas potencialmente tóxicas e levar à morte de peixes e animais essenciais à biota aquática, o que torna cada vez mais necessário o controle das fontes poluidoras e a realização de medidas para a melhoria da qualidade da água (BARRETO et al., 2014). 
De acordo com o CONAMA, os nutrientes apresentaram quantidade que se adequa à legislação imposta.

Figura 3 - Gráficos com resultados das análises de nutrientes
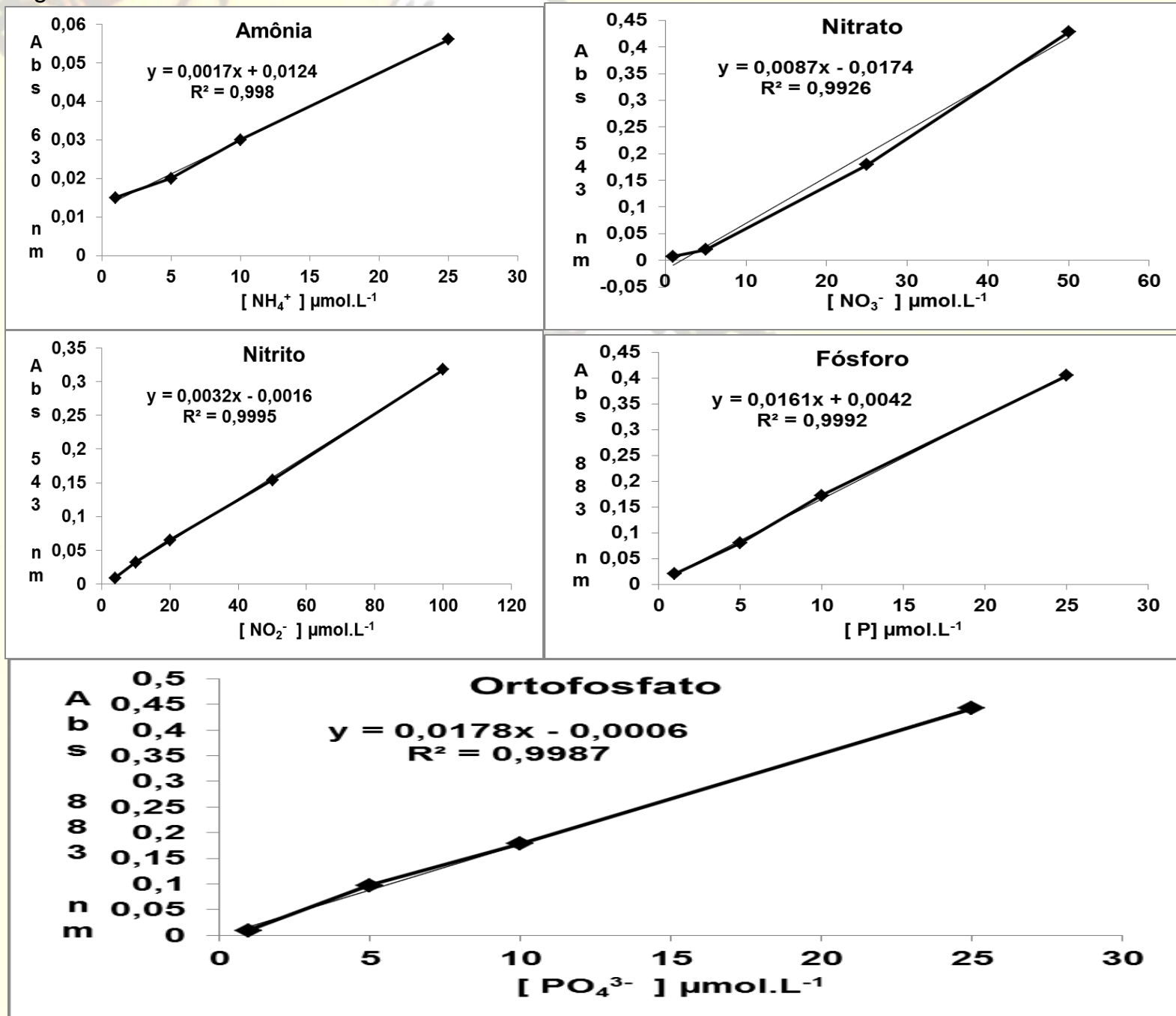

\section{CONCLUSÃO}

Os resultados obtidos foram muito satisfatórios. O equipamento teve baixo custo de montagem, a quantidade de nutrientes na água não teve resultados significativos que extrapolassem a legislação ou que interferissem na qualidade da água, pelo fato de o local de coleta fornecer água límpida e com baixa contaminação microbiológica. 


\section{REFERÊNCIAS}

APHA. Standard Methods for the Examination of Water and Wastewater. 21 ed. Washington. American Public Health Association (APHA), American Water Works Association (AWWA), Water Environment Federation (WEF), 2005.

BARRETO, L. V.; FRAGA, M. S.; BARROS, F. M.; ROCHA, F. A.; AMORIM, J. S.; DE CARVALHO, S. R. et al. Relação entre vazão e qualidade da água em uma seção de rio. Revista Ambiente \& Água, v. 9, p. 118-129, 2014. http://dx.doi.org/10.4136/ambiagua.1278

BIOTTA, P.; DANIEL L. A. Utilização de lâmpadas germicidas na desinfecção de esgoto sanitário. Revista Ambiente \& Água. An Interdisciplinary Journal of Applied Science, v. 7, n. 1, 2012.

BOUÉTARD, A.; BESNARD, A. L.; VASSAUX, D.; LAGADIC, L.; COUTELLEC, M. A.Impact of the redox-cycling herbicide diquat on transcript expression and ntioxidant enzymatic activities of the freshwater snail Lymnaea stagnalis. Aquatic Toxicology, v. 126, p. 256-265, 2013.

BRASIL. Ministério do Meio Ambiente. Conselho Nacional do Meio Ambiente. Resolução CONAMA no 357, Diário da União de 17 de março de 2005.

BUCCI, M. H. S.; OLIVEIRA, L. F. C. Índices de qualidade da água e de estado trófico na represa Dr. João Penido (Juiz de Fora, MG). Revista Ambiente \& Água, v. 9, n. 1, p. 130-148, 2014. http://dx.doi.org/10.4136/ambi-agua.1290

BRASIL. Portaria no 36/GM. Padrão de potabilidade da água destinada ao consumo humano. Brasília: Ministério da Saúde, 2000.

DONAIRE, P. P. R. Desinfecção de Águas Utilizando Radiação Ultravioleta e Fotocatálise Heterogênea. Dissertação de mestrado, UNICAMP, 2001.

FREITAS, M. B.; ALMEIDA, L. M. Qualidade da água subterrânea e sazonalidade de organismos coliformes em áreas densamente povoadas com saneamento básico precário. 1998. Disponível em: In: X CongressoBrasileiro de Águas Subterrâneas. CD-ROM, São Paulo: Sonopress-Rimo.

GOLTERMAN, H. L.; CLYMO, R. S.; OHNSTAD, M. A. M. Methods for physical and chemical analisys of freshwater. Oxford: BlackwellScientific Publications, 1978. $213 \mathrm{p}$.

GRIMALT, J. O.; DROOGE, B. L. V.; RIBES, A.; VILANOVA, R. M.; FERNANDEZ, P.; APPLEBY, P. Persistent organochlorine compounds in soils and sediments of European high altitude mountain lakes. Chemosphere, v. 54, p. 1549-1561, 2004.

KOROLEFF, F. Determination of nutrients. In: Grashof, E. \& Kremling E. (eds). Methods of seawater analysis. New York: Verlag Chemie Wenhein, p. 117-181, 1976. 
LIMA, W. P.; ZAKIA, M. J. B. Hidrologia de matas ciliares. In: RODRIGUES; R. R.; LEITÃO FILHO; H. F. (Ed.). Matas ciliares: conservação e recuperação. 2. ed. São Paulo: Editora da Universidade de São Paulo, p. 33-43, 2000.

MACKERETH, F. J. H.; HERON, J.; TALLING, J. F. Water analysis and some revised methods. Dorset: Freshwater Biology Assossiation, 1978.

MORA, M. A.; BAXTER, C.; SERICANO, J. L.; MONTOYA, A. B.; GALLARDO, J. C.; RODRÍGUEZ-SALAZAR, J. R. PBDEs, PCBs, and DDE in eggs and their impacts on aplomado falcons (Falco femoralis) from Chihuahua and Veracruz. Mexico Environmental Pollution, v. 159, p. 3433-3438, 2011.

MORMUL, R. P.; KWIATKOVSKI, A; ZERBINI, D. L. N.; FREITAS, A. A.; ALMEIDA, A. C. G. Avaliação da qualidade da água em nascentes da favela São Francisco de Campo Mourão/PR. Revista Saúde e Biologia, v. 1, n. 1, p. 36-41, 2006.

NORDBERG, G. F.; GOYER, R. A.; CLARKSON, T. W. Impact of effects of acid precipitation on toxicity of metals. Environmental Health Perspectives, v. 63, p. 169180, 1985.

SILVA, R. T.; PORTO, M. Gestão urbana e gestão das águas: caminhos da integração. Estudos Avançados, v. 17, n. 47, 2003.

TANG, Z.; HUANG, Q.; YANG, Y.; ZHU, X.; FU, H. Organochlorine pesticides in the lower reaches of Yangtze River: Occurrence, ecological risk and temporal trends. Ecotoxicology and Environmental Safety, v. 87, p. 89-97, 2013.

TUNDISI, J. G. Águas Doces no Brasil. São Paulo: Ed. Escrituras, 2006.

VON SPERLING, Marcos. Princípios do Tratamento Biológico de Águas Residuárias - Lagoas de Estabilização, v.03. Minas Gerais: ABES, 1996. 